2019 Global Fashion Management Conference at Paris Proceedings: 799-803 (July 2019) https://doi.org/10.15444/GFMC2019.08.01

\title{
ARE NEW DIGITAL INFLUENCERS RUINING YOUR BUSINESS? THE EFFECTS OF NEGATIVE WORD-OF-MOUTH INITIATED BY SOCIAL MEDIA NEW INFLUENCERS IN FASHION ON CONSUMERS' INTENTIONS TO PURCHASE AND RECOMMEND THE BRAND
}

\author{
Daniela Langaro, Instituto Universitário de Lisboa (ISCTE-IUL), Business Research \\ Unit (BRU-IUL), Portugal \\ Sandra Maria Correia Loureiro, Instituto Universitário de Lisboa (ISCTE-IUL), \\ Business Research Unit (BRU-IUL), Portugal ${ }^{1}$ \\ Ana Beatriz Paula, Instituto Universitário de Lisboa (ISCTE-IUL), Portugal
}

\begin{abstract}
Introduction

The rise of social media new influencers (e.g. bloggers, instagrammers and youtubers) has imprinted major impact in marketing communication strategies, with companies realizing the potential of fostering relationships with these new digital influencers (Acar \& Polonsky, 2007). The rationale behind doing marketing with influencers lays on reaching their audiences, while leveraging on influencers' credibility, referent and expert power for communicating brand messages (Tuten \& Solomon, 2017). While communicating with their audiences, the new influencers tend to share brand related messages. Among them are product reviews which are propagated by means of electronic word-of-mouth (e-WOM) using media resources like Instagram posts, Instagram stories or YouTube vlogs.
\end{abstract}

While evaluating the effects of new influencers, previous studies have supported the argument towards their positive consequences for the brands that they propagate, concerning word of mouth and consumers' purchase intentions (e.g., Nunes et al, 2018; Cheung, Lee, \& Rabjohn, 2008; Hsu, Lin, \& Chiang, 2013; East, Hammond, \&Wright, 2008; Vásquez,, Suárez, \& Belén, 2013).

However, new influencers are also known for criticizing products and writing negative reviews, when product experiences fail to deliver. As previous studies have not yet evaluated the effects of these negative product reviews, in the current study the authors evaluate to what extent negative product reviews created by social media new influencers affect their audiences' intentions to purchase and recommend. While investigating the effects proposed, the constructs of perceived self-brand connection and influencers' credibility were considered for their moderating effects.

\section{Theoretical Background}

Web 2.0 technologies have allowed a shift in brand communications, with brand related content being co-created between marketers and consumers (Kaplan \& Haenlein, 2010). In this context, electronic word-of-mouth (e-WOM) is born as an expression of brand related content which is digitally distributed to potentially large audiences (Goldsmith \& Horowitz, 2006). Its relevance is associated to the significant effects that it imprints

\footnotetext{
${ }^{1}$ sandramloureiro@netcabo.pt
} 
on consumers' intentions regarding brands' purchase and recommendations (Sashi, 2012).

Previous studies distinguish between negative and positive valences, with negative eWOM being associated to negative feelings and opinions that are voiced in the digital context. The current study focuses on the negative e-WOM as this is a topic which is still scarcely investigated in the digital context and presents diverging results in traditional contexts. On one hand, studies in traditional WOM contexts indicate that consumers are often more likely to pay attention to negative information rather than positive, as the threat of potential loss is seen as more influential than the hope of a potential gain (Kahneman and Tversky, 1984) - this could mean that negative WOM has a greater effect on consumers than positive. However, as positive WOM occurs more frequently in the marketplace than negative WOM, so consumers are generally faced with and persuaded to have a positive attitude towards products in general (Martin, 2017). This preexisting positive attitude can serve as a barrier to the effects of negative WOM, and thus negative information may be less successful in changing consumers' views than positive (Sweeney, Soutar, \& Mazzarol, 2012).

The current study envisions to address this gap and some of its diverging aspects. While doing that the focus lies on social media new influencers and evaluates whether negative e-WOM initiated by these influencers would negatively impact their audiences regarding their intentions to purchase (Cheung, et al., 2008) and recommend the brand (Lee \& Youn, 2009). Moreover, while evaluating these effects, moderation conditions suggested in the literature were considered, namely:

- Self-brand connection: when consumers perceive a high self-brand connection the effects of negative word-of-mouth are diminished (East, Hammond, \& Wright, 2008; East, Romaniuk, Chaudhary, \& Uncles, 2017; Cheng, White, \& Chaplin, 2012),

- Perceived source credibility: when consumers perceive the new influencer as a credible source the effects of negative word-of-mouth tend to be more significant (Hsu, Lin, \& Chiang, 2013).

Based on above mentioned studies, the following hypotheses were proposed:

H1a: Negative eWOM initiated by social media new influencers has stronger effects than Positive eWOM on consumers' future purchase intentions.

H1b: Negative eWOM initiated by social media influencers has stronger effects than Positive eWOM on consumers' future recommendation intentions.

H2a: The effects of Negative eWOM initiated by social media new influencers on future purchase intentions are significantly lower when consumers nurture a high level of self-brand connection.

H2b: The effects of Negative eWOM initiated by social media new influencers on future recommendation intentions are significantly lower when consumers nurture a high level of self-brand connection. 
H3: The effects of Negative eWOM initiated by social media new influencers on future purchase intentions are significantly higher when the influencer is perceived for its high credibility.

\section{Methodology}

An online survey following an experimental design was implemented with 2 groups (positive WOM and negative WOM) of respondents being compared for differences inbetween groups.

The stimuli were developed based on posts typically created by social media new influencers (with negative and positive valence), with patterns regarding content and format being captured in a preparatory qualitative phase and adapted to the stimuli. The final stimuli resulted from a pre-test which intended to validate the understanding. liking and valence of posts. In total eight posts were created based on four different existing products (shoe, clothes and cosmetics - mascara and foundation). Half of the posts were phrased in a positive manner (positive WOM) and other half were phrased in a negative manner (negative WOM). All remaining aspects were the same, including the characteristics that were recommended.

Items to measure the self-brand identification, source credibility, purchase intention and recommendation intentions were sourced respectively from Escalas and Bettman (2005), Prendergast, Ko and Yuen (2010), Vásquez, Suárez, and Belén (2013), Coyle and Thorson (2001) and Hsu, Lin and Chiang (2013) and measured in a 7 points Likerttype scale with end-points varying between (1) Not agree at all and (7) Completely agree.

The link to the survey was prepared in an online platform (www.qualtrics.com) and distributed in social media pages. It aimed to recruit females aged between 16 and 35 years old, who use social media and new influencers. The target profile mirrors the audiences that most strongly claim to follow influencers in fashion and beauty, which is the industry in focus in the current research, due to the relevant presence of influencers (DePhillips \& Son, 2017; Jones \& Kang, 2016). After accessing the link to the questionnaire, respondents were randomly allocated to one of the conditions (positive WOM or negative WOM).

Initial statistical analyses were performed for validating the scales regarding their unidimensionality and reliability, using IBM SPSS statics V.25. The constructs were checked for their reliability considering a minimum value of 0.65 for Cronbach's alpha. The value of the Cronbach's alpha if item deleted was also inspected. For validating unidimensionality a three-factor solution was considered with factor loadings being required to be high loaded (above 0.5 ) in only one component. Hypotheses were tested using Students t-test, as the data were normally distributed (as concluded in KolomovSmirnov Test).

\section{Results and Discussion}

A total of 150 valid answers were obtained. Constructs were validated for internal consistency and unidimensionality. For testing hypotheses $H 1 a$ and $H 1 b$ total sample was considered and respondents exposed to NWOM were compared with others exposed to PWOM. Differences between groups were analyzed with both hypotheses being accepted for the significant differences $(p<0.1)$ obtained. For testing hypotheses 
$H 2 a$ and $H 2 b$ only consumers exposed to negative posts were considered, being split in 2 groups, based on their level of self-congruity (high $>4$ in 7 points Likert-type scale). Differences between groups were analyzed with significant results obtained $(p<0.05)$. For testing $H 3$, only consumers exposed to negative WOM were considered, being split in 2 groups, based on their level of perceived credibility (high $>4$ in 7 points Likert scale). Differences between groups were analyzed, with significant differences $(p<0.1)$ obtained. There fore $H 3$ was accepted.

The results indicate that negative eWOM propagated by new influencers in fashion (e.g. bloggers, instagrammers, youtubers) has significant effects on consumers intentions regarding purchase and recommendation, when compared with positive eWOM. Moreover, the negative effects of eWOM on consumers' intentions regarding purchase and recommendation are significantly higher when consumers nurture a lower level self-congruity with the brand. Finally, the negative effects tend to be higher when the new influencer is perceived as high in credibility.

\section{Conclusions}

The study highlights the significant effects that negative eWOM initiated by new influencers in fashion may have on consumers intentions regarding purchasing and recommending the brand. These effects tend to be stronger when the new influencer is acknowledged for its credibility. On the other hand, the current study also highlights the importance of self-brand connection for shielding the brand against the effects of negative eWOM, as consumers reveal more tolerance to the negative messages when they perceive themselves closely related to the brand.

Findings need to be understood within the scope of limitation related to sample characteristics (e.g. female sample), geography and product categories. Future studies should try to address those limitations by means of extending the study to other contexts and allowing that comparisons are drawn.

Keywords: word-of-mouth, online fashion influencer, intentions to purchase, recommend the brand

Acknowledge: This work was supported by Fundação para a Ciência e a Tecnologia, grant UID/GES/00315/2019

\section{References}

Acar, A. \& Polonsky, M. (2007). Online social networks and insights into marketing communications. Journal of Internet Commerce, 6(4), 55-72

Cheng, S. Y. Y., White, T. F., \& Chaplin, L. G. (2012). The effects of self-brand connections on responses to brand failure: A new look at the consumer-brand relationship. Journal of Consumer Psychology, 22, 280-288.

Cheung, C. M.K., Lee, M. K.O., \& Rabjohn, N. (2008). The impact of electronic wordof-mouth - The adoption of online opinions in online customer communities. Internet Research, 18, 242.

Coyle, J. R. \& Thorson, E. (2001). The effects of progressive levels of interactivity and vividness in web marketing sites. Journal of Advertising, 30, 63-77.

DePhillips, A. \& Son, J. (2017). Millennials' Fashion Consumption: Who Are Fashion Opinion Leaders in Social Media? International Textile and Apparel Association (ITAA) Annual Conference Proceedings, 84. Published online. 
East, R, Hammond, K., \& Wright, M. (2008). Measuring the impact of positive and negative word of mouth on brand purchase probability. International Journal of Research in Marketing, 25(03), 215-224

East, R., Romaniuk, J., Chaudhary, R., \& Uncles, M. (2017). The Impact of Word of Mouth on Intention to Purchase Currently Used and Other Brands. International Journal of Market Research, 59(3),321-334

Escalas, J. E., \& Bettman, J. R. (2005). Self-construal, reference groups, and brand meaning. Journal of Consumer Research, 32, 378-389.

Goldsmith, R. E., \& Horowtiz, D. (2006). Measuring Motivations for Online Opinion Seeking. Journal of Interactive Advertising, 6, 2-14.

Hsu, C., Lin, J., \& Chiang, H. (2013). The effects of blogger recommendations on customers' online shopping intentions. Internet Research, 23, 69-88.

Jones, A., \& Kang, J. (20169. No Longer in Vogue? Exploration of Motivations

Underlying Millennials' Information Seeking Through Digital Fashion Media. International Textile and Apparel Association (ITAA) Annual Conference Proceedings ( $p .105)$.

Kaplan, A. \& Haenlein, M. (2010). Users of the world, unite! The challenges and opportunities of Social Media. Business Horizons, 53, 59-68.

Kahneman, D., \& Tversky, A. (1984). Choices, values and frames. American Psychologist, 39, 341-350.

Martin, W. (2017). Positive vs Negative Word-of-mouth: Effects on Receivers. Academy of Marketing Studies Journal, 21(2), 1-10.

Nunes, R., Ferreira, J., Freitas, A., \& Ramos, F. (2018). The effects of social media opinion leaders' recommendations on followers' intention to buy. Revista Brasileira de Gestão de Negócios, 20, 57-73.

Prendergast, G., Ko, D., \& Yuen, S. Y. V. (2010). Online word of mouth and consumer purchase intentions. International Journal of Advertising, 29, 678-708.

Sashi, C. M. (20129. Customer engagement, buyer-seller relationships, and social media. Management Decision, 50, 253-272.

Sweeney, J.C., Soutar, G.N., \& Mazzarol, T. (2012). Word of mouth: measuring the power of individual messages. European Journal of Marketing, 46, 237-257.

Tuten, T. L., \& Solomon, M. R. (2017). Social media marketing. Sage.

Vásquez, R., Suárez, L., \& Belén, A. (2013). The Word of Mouth Dynamic: How Positive (and Negative) WOM Drives Purchase Probability: An Analysis of Interpersonal and Non-Interpersonal Factors. Journal of Advertising Research, 53(1), 43-60. 